\title{
Structure-function analysis of the $3^{\prime}$ stem-loop of hepatitis C virus genomic RNA and its role in viral RNA replication
}

\author{
MINKYUNG YI and STANLEY M. LEMON \\ Department of Microbiology and Immunology, The University of Texas Medical Branch at Galveston, Galveston, Texas 77555-1019, USA
}

\begin{abstract}
Previous studies indicate that the $3^{\prime}$ terminal 46 nt of the RNA genome of hepatitis C virus (HCV) are highly conserved among different viral strains and essential for RNA replication. Here, we describe a mutational analysis of the $3^{\prime}$ terminal hairpin (stem-loop I) that is putatively formed by this sequence and demonstrate its role in replication of the viral RNA. We show that single base substitutions within the 6-nt loop at positions adjacent to the stem abrogate replication of a subgenomic RNA, whereas substitutions in the three apical nucleotides were well tolerated without loss of replication competence. Single point mutations were also well tolerated within the middle section of the duplex, but not at the penultimate nucleotide positions near either end of the stem. However, complementary substitutions at the -19 and -28 positions (from the 3 ' end) restored replication competence, providing strong evidence for the existence of the structure and its involvement in RNA replication. This was confirmed by rescue of replicating RNAs from mutants containing complementary 10-nt block substitutions at the base of the stem. Each of these RNAs contained an additional $U$ at the $3^{\prime}$ terminus. Further experiments indicated a strong preference for $U$ at the 3' terminal position (followed in order by C, A, and G), and a G at the -2 position. These features of stem-loop I are likely to facilitate recognition of the $3^{\prime}$ end of the viral RNA by the viral RNA replicase.
\end{abstract}

Keywords: Hepatitis C virus; mutational analysis; replication; RNA structure

\section{INTRODUCTION}

Persistent infection with hepatitis C virus (HCV) is an important cause of chronic liver disease in the United States and many other countries. Infections with this hepatotropic flavivirus are associated with necroinflammatory liver injury, progressive fibrosis, and, in the most severely affected patients, cirrhosis and hepatocelluar carcinoma (Seeff 1997; Alter et al. 1998). Recombinant interferon- $\alpha$, either alone or in combination with ribavirin, is widely used to treat $\mathrm{HCV}$ infections. However, these drugs eliminate the infection in less than $50 \%$ of persons with chronic hepatitis (McHutchison et al. 1998; Lindsay et al. 2001). The development of more effective antiviral agents for the treatment of chronic hepatitis $\mathrm{C}$ is urgently awaited, but has been slowed by the lack of cell culture systems that are fully permissive for viral replication as well as a lack of small animal models of the disease. Although the lack of permissive cell cultures has

Reprint requests to: Stanley M. Lemon, Department of Microbiology and Immunology, The University of Texas Medical Branch at Galveston, 301 University Boulevard, Galveston, TX 77555-1019, USA; e-mail: smlemon@utmb.edu.

Article and publication are at http://www.rnajournal.org/cgi/doi/ 10.1261/rna.2144203. made difficult characterization of this virus and its replicative life cycle, much has been learned from the characterization of the viral genome and by in vitro expression of the viral proteins from recombinant cDNA (Major and Feinstone 1997; Blight et al. 1998; De Francesco 1999). More, recently, the development of subgenomic HCV replicons that are capable of replication in human hepatoma (Huh7) cells has provided powerful new approaches to characterizing the molecular processes involved in replication of the viral RNA (Lohmann et al. 1999).

$\mathrm{HCV}$ is presently classified as the sole member of the Hepacivirus genus in the family Flaviviridae. Its genome is a single-stranded RNA molecule $\sim 9.6 \mathrm{~kb}$ in length with positive-sense polarity (Choo et al. 1989, 1991). This RNA has a $5^{\prime}$ nontranslated RNA (5'NTR) segment of $\sim 342 \mathrm{nt}$ and a $3^{\prime} \mathrm{NTR}$ of $\sim 225 \mathrm{nt}$. These two regions are among the most highly conserved sequences in the HCV genome (Bukh et al. 1995). They flank a single large open reading frame that encodes at least 10 proteins, including (in a $5^{\prime}$ to $3^{\prime}$ direction) the viral structural proteins (core, E1, E2, and p7) and at least 6 nonstructural proteins (NS2, NS3, NS4A, NS4B, NS5A, NS5B; Major et al. 1997; Blight et al. 1998; De Francesco 1999). However, only the polypeptides spanning NS3 to NS5B are required for replication of the viral RNA (Lohmann et al. 1999). Given analogies with other positive- 
strand RNA viruses, and evidence for interactions of these proteins with each other as well as with intracellular membranes, these nonstructural proteins are likely to participate in formation of a large membrane-bound, macromolecular replicase complex containing multiple enzymatic activities (Egger et al. 2002; Mottola et al. 2002). The NS5B protein, which is located at the carboxy end of the viral polyprotein, is an RNAdependent, RNA polymerase (RdRp), and forms the catalytic core of this complex. The structure of NS5B has been well characterized, and its enzymatic activities have been studied in detail using recombinant proteins, usually truncated at the carboxy terminus in order to remove a probable membrane-interaction domain and increase the solubility of the expression product (Lohmann et al. 1998; Ferrari et al. 1999; Oh et al. 1999).

Recombinant NS5B proteins are known to be capable of primer-independent initiation of RNA synthesis on a variety of virus-specific and nonspe-

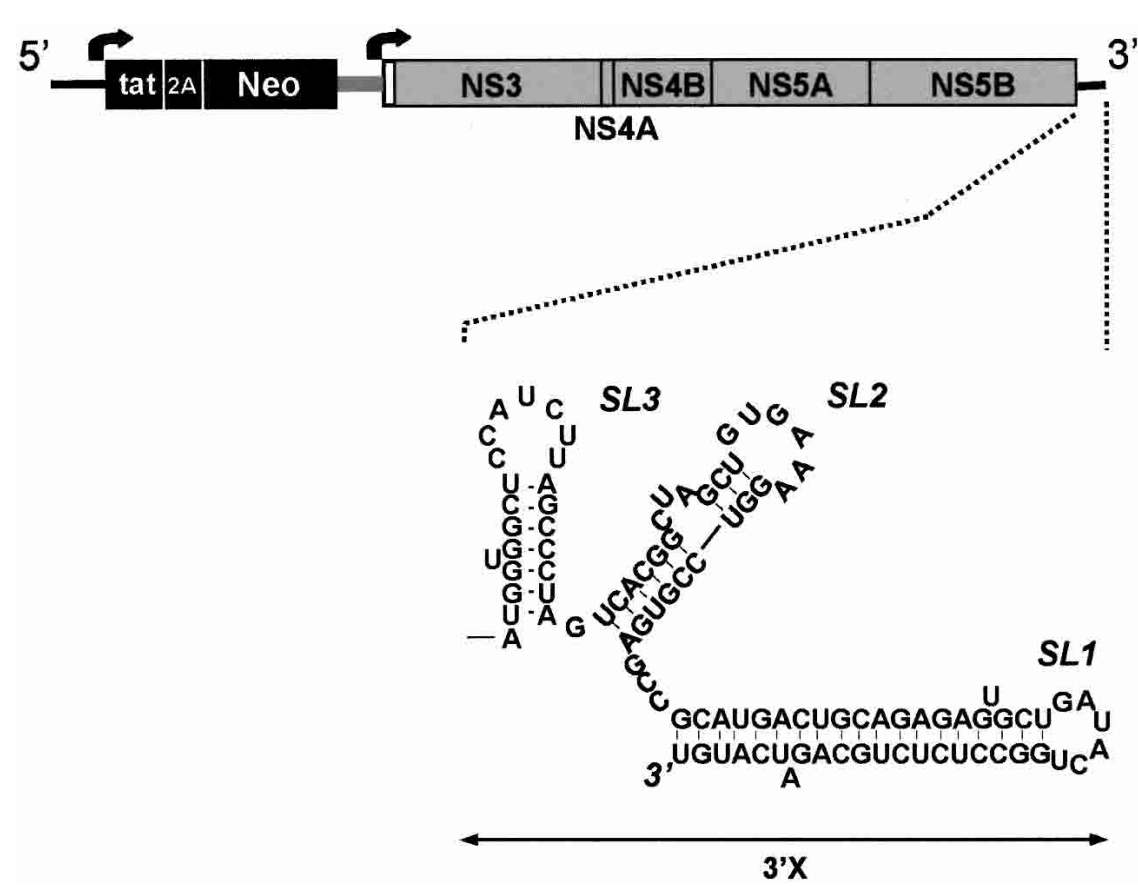

FIGURE 1. A schematic depicting the organization of the dicistronic Ntat2ANeo(SI) replicon RNA (Yi et al. 2002) in which mutations were created within the $46 \mathrm{nt}$ that putatively form a $3^{\prime}$ terminal stem-loop structure, SL1. An expanded view below the map of the replicon shows the predicted RNA secondary structure within the $3^{\prime} \mathrm{X}$ domain of the $3^{\prime} \mathrm{NTR}$ (Blight and Rice 1997). cific RNA templates (Lohmann et al.

1998; Ferrari et al. 1999; Oh et al. 1999).

However, there are conflicting descriptions of the precise site of initiation of negative-strand transcription on virusspecific templates (Oh et al. 2000; Hong et al. 2001; Kim et al. 2002; Shim et al. 2002). Although the $3^{\prime}$ NTR is both highly conserved and rich in structure (Yamada et al. 1996; Blight and Rice 1997; Ito and Lai 1997), purified, recombinant NS5B protein binds to the upstream NS5B coding sequence with significantly greater affinity than it does to this segment of the viral genomic RNA (Kim et al. 2002). Thus, the mechanisms by which the HCV RdRp recognizes the terminal sequences of the genomic RNA for proper and specific initiation of negative-strand RNA synthesis remain controversial.

Evidence derived from experiments done in vitro suggests that the $3^{\prime} \mathrm{NTR}$ may be required for transcription of genome-length RNA by a purified NS5B RNA dependent RNA polymerase (Oh et al. 1999, 2000). A surprising finding, however, was that transcription of the negative-strand RNA product was initiated $21 \mathrm{nt}$ upstream of the $3^{\prime}$ terminus of the positive-strand template (Oh et al. 2000), within the single-stranded segment of a stem-loop (stem-loop 1, or SL1) that is putatively formed by the $3^{\prime}$ terminal $46 \mathrm{nt}$ of the genomic RNA (Fig. 1; Blight and Rice 1997; Ito and Lai 1997). Other in vitro studies also suggest that primer-independent, de novo transcription of RNA from templates containing the $3^{\prime}$ NTR sequences may involve the internal initiation of negative-strand RNA synthesis, but at other sites (Kim et al. 2002; Pellerin et al. 2002). However, other investigators have shown that transcription can in fact be initiated de novo by a recombinant NS5B polymerase in vitro at the $3^{\prime}$ end of short oligonucleotide templates representing the 3' terminus of the positive-strand genomic RNA (Shim et al. 2002).

Despite substantial differences in these in vitro studies, there is convincing evidence that the $3^{\prime}$ terminal nucleotides of the positive-strand template influence both the efficiency of transcription as well as the site of transcriptional initiation (Kim et al. 2002; Shim et al. 2002). Such data are consistent with a role for the $3^{\prime}$ terminal sequences of the viral RNA in recognition of the template by the replicase complex. This hypothesis is further supported by the fact that deletion of the $3^{\prime}$ terminal $46 \mathrm{nt}$ destroys the ability of otherwise infectious synthetic genome-length HCV RNA to initiate infection in intrahepatically inoculated chimpanzees (Yanagi et al. 1999). The deletion of this sequence also abrogates the ability of subgenomic replicon RNAs to replicate in cultured cells (Friebe and Bartenschlager 2002; Yi and Lemon 2002). Interestingly, this 46-nt sequence putatively forms a stable stem-loop structure at the extreme $3^{\prime}$ terminus of the genomic RNA (Fig. 1; Kolykhalov et al. 1996; Tanaka et al. 1996). The existence of SL1 is supported by results of studies mapping sites of ribonuclease cleavage or chemical modification within synthetic RNA transcripts (Blight and Rice 1997; Ito and Lai 1997). However, there is 
a paucity of data from mutational analyses or phylogenetic comparisons to support the computer predictions of the secondary structure assumed by this highly conserved segment of the genome. We have thus focused our attention on SL1 in an effort to determine whether the predicted structure is functionally required for replication of the viral RNA.

As mentioned above, several nonstructural proteins other than NS5B are likely to contribute to the functional replicase complex (Blight et al. 1998; De Francesco et al. 2000; Egger et al. 2002; Mottola et al. 2002). Thus, there are limitations on what can be learned about viral RNA replication from in vitro transcription reactions that contain only a single purified viral protein, NS5B, such as those that were characterized in the studies described above (Oh et al. 2000; Hong et al. 2001; Kim et al. 2002; Shim et al. 2002). We have studied the requirements for the SL1 structure during replication of subgenomic HCV RNAs in human hepatoma cells (Lohmann et al. 1999; Ikeda et al. 2002). Because the autonomous amplification of these selectable replicons appears to follow a process that is very similar if not identical to that mediating the replication of viral RNA, the results of this analysis are likely to be relevant to the process by which the viral genome is recognized by the replicase complex in virus-infected hepatocytes.

\section{RESULTS}

\section{The sequence comprising SL1 is essential for replication of HCV RNA}

To assess the role of the SL1 structure in viral RNA replication, we mutated this sequence within the background of a replication-competent, dicistronic, subgenomic RNA, Ntat2ANeo(SI) (Fig. 1) that expresses the human immunodeficiency virus (HIV) transcriptional transactivator tat. The replication of this RNA induces expression of secreted alkaline phosphatase (SEAP) in proportion to intracellular RNA abundance following transfection of human hepatoma cells (En5-3 cells) that express SEAP under transcriptional control of the HIV long terminal repeat promoter. A detailed description of this replicon system and its use in reverse molecular genetics analysis of HCV RNA replication has been reported elsewhere (Yi and Lemon 2002; Yi et al. 2002). The transfection of synthetic Ntat2ANeo(SI) transcripts into En5-3 cells leads to replication of the RNA and the intracellular expression of tat activity. This in turn results in an immediate and substantial secretion of SEAP into the cell culture supernatant fluids, resulting within $12 \mathrm{~h}$ in the presence of SEAP activities that are up to 100-fold that present in supernatant fluids from mock-transfected cells.

Figure 2A shows SEAP activity secreted over successive 24-h periods following transfection of En5-3 cells with the RNA. The results have been normalized to SEAP activity levels produced during the first $24 \mathrm{~h}$ after transfection, as during this period of time SEAP expression is due to translation of the transfected RNA and is not dependent on RNA replication (Yi and Lemon 2002; Yi et al. 2002). The figure shows that the secretion of SEAP increases gradually over the next several days, reaching a plateau within 7 days of transfection. Cells transfected with a replication-defective Ntat2ANeo(SI) mutant containing a deletion in the NS5B sequence (Fig. 2A, $\Delta$ GDD mutant) express a similar high level of SEAP activity during the first 48-72 h after transfection, but the secretion of SEAP by these cells subsequently drops dramatically and approaches that produced by normal En5-3 cells within 7 days. Also shown in Figure $2 \mathrm{~A}$ are the results of SEAP assays carried out on media collected from cells transfected with $\Delta$ SL1, a mutant derived from Ntat2ANeo(SI) in which all of the sequence contributing to stem-loop SL1 has been deleted (Yi and Lemon 2002). The pattern of SEAP secreted by these cells parallels that produced by cells transfected with the $\Delta$ GDD mutant. 
These results confirm the essential nature of the SL1 sequence to viral RNA replication. As we and others have reported previously (Friebe and Bartenschlager 2002; Yi and Lemon 2002), the failure of subgenomic RNAs lacking this $3^{\prime}$ terminal sequence to replicate cannot be attributed either to decreased stability of the RNA, or to a reduction in translation mediated by the internal ribosome entry site of HCV. Although the Ntat2ANeo(SI) RNA directs the expression of neomycin phosphotransferase as a selectable marker (Fig. 1), G418 was not included in the culture media in transient transfections such as shown in this experiment.

Figure $2 \mathrm{~B}$ presents these results differently, relating the SEAP activity expressed by cells transfected with the parent Ntat2ANeo(SI) RNA and its derivative, the $\Delta$ SL1 mutant, to that expressed by cells transfected with the $\Delta$ GDD mutant. This figure demonstrates the exponential increase in SEAP secretion induced by the $\mathrm{Ntat} 2 \mathrm{ANeo}(\mathrm{SI}) \mathrm{RNA}$ relative to that induced by the related $\Delta \mathrm{GDD}$ mutant. Figure $2 \mathrm{~B}$ also demonstrates the complete failure of the $\Delta$ SL1 mutant to replicate. This was confirmed by a lack of surviving G418- resistant cells when attempts were made to transduce G418 resistance with this RNA. In contrast, the parental Ntat2ANeo(SI) RNA gave rise to G418-resistant cells at high efficiency ( $>10^{4}$ colonies $/ 10^{6}$ transfected cells).

\section{Point mutations in the loop sequence of SL1 have a} variable effect on replication of HCV RNA

The sequence of the loop in the SL1 structure in Ntat2ANeo(SI) is comprised of 6 nt: 5'-GAUACU-3' (Fig. 1 ). To determine how stringently this sequence is required for Ntat2ANeo(SI) replication, we constructed a mutant (BLoop) in which each of the positions within the loop was mutated to its Watson-Crick complement (Fig. 3A). The exchange of the native $5^{\prime}$-GAUACU-3' loop sequence with $5^{\prime}$-CUAUGA-3' in this mutant led to a complete loss of replication capacity in the transient transfection assay, as shown in Figure 3B. This figure depicts the actual amount of SEAP produced over successive 24 -h periods by cells transfected with the mutant RNA, as well as cells transfected
A

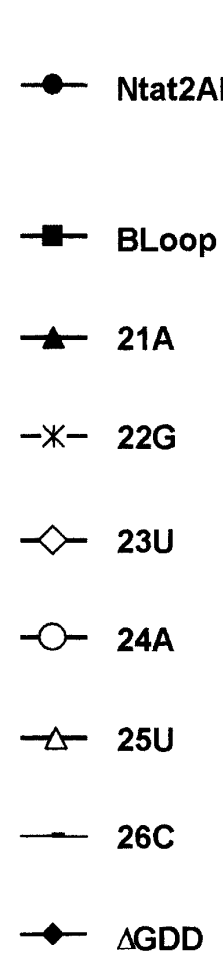

$\mathbf{5}^{\prime}$

- GCAUGACUgCAGAGAGGCUGA ${ }^{26} \mathrm{U}^{24}$

3' gaucuguacugacGUCÚCUCCGG $U_{21} \mathrm{C}_{22}^{\mathrm{A}_{23}}$

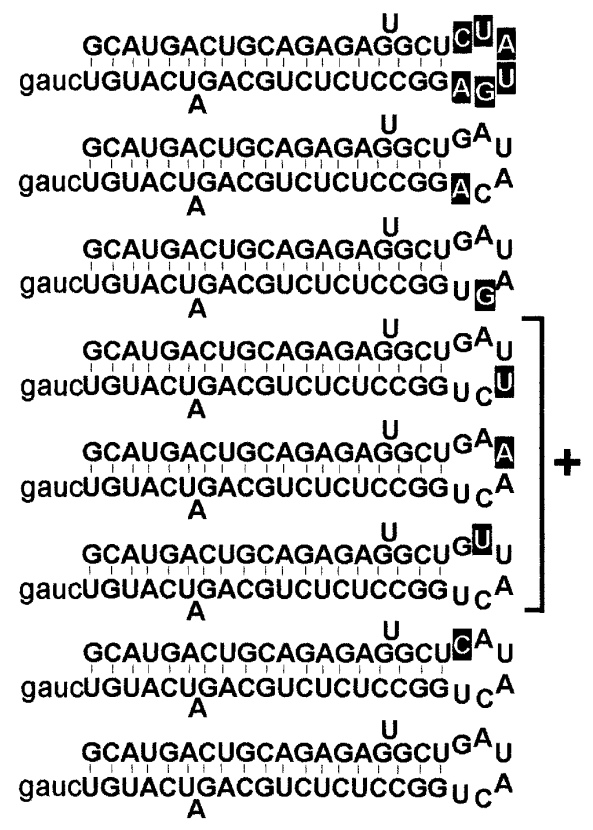

B

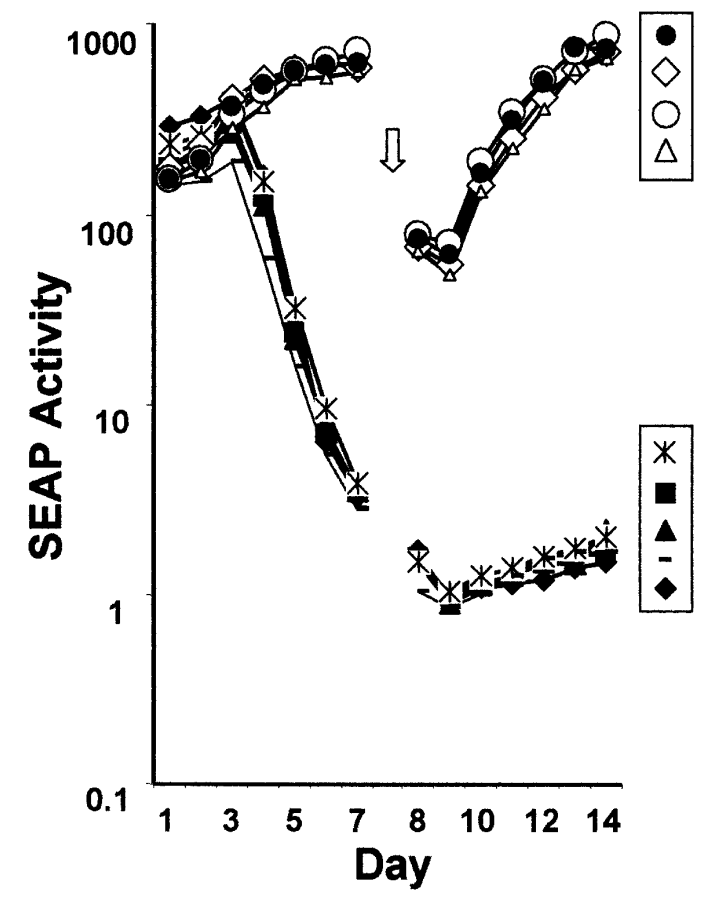

FIGURE 3. Transient transfection of En5-3 cells with Ntat2ANeo(SI) and related mutants containing nucleotide substitutions within the putative loop segment of the SL1 stem-loop located at the $3^{\prime}$ end of the $3^{\prime}$ NTR. (A) Schematic showing the substitution mutations within the loop segment. Nucleotides are numbered according to their position from the $3^{\prime}$ end of the RNA. (B) SEAP activity present in supernatant culture fluids collected at 24-h intervals following transfection of En5-3 cells with Ntat2ANeo(SI) (filled circles), BLoop, in which the entire loop sequence was replaced with its complement (filled squares), or mutants with individual nucleotide substitutions: 21A (filled triangles), 22G (asterisks), 23U (open diamonds), 24A (open circles), 25U (open triangles) or 26C (dash). Results are also shown following transfection of Ntat2ANeo(SI) containing the $\Delta$ GDD mutation that is lethal for replication (filled diamond). The transfected cells were passaged after collection of the supernatant fluid at day 7 (open arrow). 
with the replication-competent parent, Ntat2ANeo(SI), and the replication-defective $\Delta$ GDD mutant. There was little difference in the early expression of SEAP by these cells (up to $48 \mathrm{~h}$ posttransfection), indicating that there is little difference in the efficiency of transfection or translation of these RNAs. Beyond $72 \mathrm{~h}$, however, when continued high-level secretion of SEAP is dependent upon replication of the RNA (Fig. $2 \mathrm{~A}$ ), there was a marked difference in SEAP expression induced by the BLoop mutant and the parental Ntat2ANeo(SI) RNA. Failure of the BLoop mutant to replicate was indicated by a sustained decline in SEAP expression, matching that observed with the $\Delta \mathrm{GDD}$ mutant (Fig. 3B). This result suggests that the sequence of the SL1 loop is very important for RNA replication.

We next investigated the effect of single nucleotide substitutions within the loop sequence (Fig. 3A). Surprisingly, individual base substitutions to the Watson-Crick complement were well tolerated at some positions, whereas other single base substitutions were lethal for replication in this assay (Fig. 3B). No intermediate phenotypes were detected in these experiments (Fig. 3B). Transversion substitutions at the base of the loop, involving the substitution of $21 \mathrm{U}, 22 \mathrm{C}$, or 26G (nucleotide positions numbered from the 3 ' end of the genome) to $21 \mathrm{~A}, 22 \mathrm{G}$, and $26 \mathrm{C}$, respectively, completely abrogated replication of the RNA. In contrast, similar substitutions at the internal loop positions, with substitutions at $23 \mathrm{~A}, 24 \mathrm{U}$, and $25 \mathrm{~A}$ to $23 \mathrm{U}, 24 \mathrm{~A}$, and $25 \mathrm{U}$, respectively, had no discernible effect on SEAP expression and thus replication of the RNA. These results suggest that interactions between the bases in the lower half of the loop may be important for defining the conformation of the loop and the recognition of the $3^{\prime}$ terminus of the RNA by the replicase complex. Alternatively, this part of the stem-loop structure might interact directly with a component of the replicase complex. In contrast, the top of the loop does not appear to be involved in critical RNA-RNA or RNA-protein interactions given the apparent plasticity of the apical $23 \mathrm{~A}, 24 \mathrm{U}$, and $25 \mathrm{~A}$ residues.

Because $20 \mathrm{G}$ and $27 \mathrm{U}$ are predicted by MFOLD to form a G-U closing pair at the base of the loop (Fig. 3A), it is unlikely that $21 \mathrm{U}$ and $26 \mathrm{G}$ form a similar base pair. However, to gain further insight into the requirements for these two bases and potential interactions between them, we evaluated a second series of mutants with additional sub- stitutions at $26 \mathrm{G}$, or both $26 \mathrm{G}$ and $21 \mathrm{U}$ (Fig. 4). The substitution of $26 \mathrm{G}$ with either $\mathrm{C}, \mathrm{A}$, or $\mathrm{U}$ led to a loss of detectable replication in the transient transfection assay (data not shown). This confirms the importance of this particular nucleotide for replication of the RNA, as suggested by the data shown in Figure 3. Furthermore, replication competence was not restored to the $26 \mathrm{U}$ mutant by a second, potentially compensatory $21 \mathrm{G}$ substitution (Fig. 4, mutant $21 \mathrm{G}-26 \mathrm{U}$ ). This indicates that a $21 \mathrm{G}-26 \mathrm{U}$ pair cannot functionally replace $21 \mathrm{U}$ and $26 \mathrm{G}$.

Despite the absence of detectable replication in transient transfections with the 21G-26U mutant, it was possible to select G418-resistant cell colonies following transfection with this RNA. Although time consuming and tedious, the selection of G418-resistant cells is a more suitable approach for detection of a small population of cells that support the replication of transfected RNAs below the limit of detection in the transient assays depicted in Figures 2 and 3 (Friebe and Bartenschlager 2002; Ikeda et al. 2002; Pietschmann et al. 2002). The ability to select antibiotic-resistant cells following transfection of mutated replicons expressing neomycin phosphotransferase also allows for the identification of primary or second-site revertants that are capable of 
efficient RNA replication. RNAs like the 21G-26U mutant that fail to generate levels of SEAP expression that are indicative of replication of the RNA in transient transfection assays, but that remain capable of giving rise to G418-resistant cell clones following antibiotic selection, can be considered to contain mutations that are "pseudo-lethal" for replication. 21G-26U was the only mutant among those shown in Figure 4 with a pseudo-lethal phenotype. Because G418-resistant cells could not be selected with the other mutants, including the single mutant $26 \mathrm{U}$, these data suggest that the $21 \mathrm{G}$ mutation was able to rescue the replication competence of $26 \mathrm{U}$, albeit only at a low level.

Three clonally distinct G418-resistant cell lines were established from En5-3 cells transfected with the 21G-26U double mutant. The $3^{\prime}$ terminal nucleotide sequence of the replicon RNAs present in each of these cell lines was determined by sequencing cDNA obtained following amplification by RT-PCR (see Materials and Methods). In each case, the engineered $21 \mathrm{G}$ and $26 \mathrm{U}$ substitutions had reverted to the original $21 \mathrm{U}$ and $26 \mathrm{G}$ nucleotides that are present in Ntat2ANeo(SI) RNA. Interestingly, whereas in one of these revertants (Fig. 4, R1) the 3'NTR sequence was identical to that of the NtatNeo2A(SI) parent, two revertants (Fig. 4, R2 and R3) contained mutations in addition to the reversions at $21 \mathrm{U}$ and $26 \mathrm{G}$. In R2, 25A was substituted with $\mathrm{G}$ within the loop of SL1 (note that the results in Fig. 3B demonstrated that an A to $\mathrm{U}$ substitution is also tolerated at this base position). In R3, an additional A to G substitution was present within the loop sequence of a stem-loop structure, SL2, that has been proposed to exist immediately upstream of the SL1 (Fig. 1), at the 60th base position from the $3^{\prime}$ end of the genome.

When we reintroduced cDNA fragments amplified from R2 and R3 by RT-PCR into the background of Ntat2ANeo(SI), we found that RNA bearing the R2 substitution replicated as efficiently as the parental RNA in a transient transfection assay, and similar to the $25 \mathrm{U}$ mutant (Fig. 3B). RNA bearing the R3 mutation also replicated, but at a reduced level compared to the parental RNA, based on the quantity of SEAP produced by the transfected cells (data not shown). These results suggest the possibility that repair of the replication defect in 21G-26U may require a complex, multistep process involving sequential base changes. If so, the substitution found in the loop of SL2 suggests the possibility of tertiary interactions between the loop sequences of SL1 and SL2. However, further studies will be needed to properly assess this hypothesis.

\section{Structure-function correlates within the duplex stem of SL1}

To determine whether RNA replication is dependent upon the duplex structure of the stem, the specific nucleotide sequence of the RNA strands contributing to the duplex stem, or both the structure and the specific sequence, we created a series of Ntat2ANeo(SI) mutants with substitutions of short blocks of nucleotides within either the apical or basal half of the duplex (Fig. 5). The mutants SL1-A and SL1-AA contain single 10-nt block substitutions that each eliminate base pairing within the basal half of the stem. In contrast, SL1-A/AA contains both block substitutions, which are complementary and thus restore base pairing within the stem (while leaving changed the single, unpaired purine base at the seventh position from the end of the genome; Fig. 5A). As shown in Figure 5A, the mutants SL1-B, SL1-BB, and SL-1-B/BB contain block substitutions that similarly alter and restore base pairing within the apical half of the stem.

When these mutant RNAs were transfected into En5-3 cells, none gave rise to sustained levels of SEAP secretion, indicating that each of these Ntat2ANeo(SI) mutants was either nonviable or otherwise severely handicapped in its replication capacity. These results suggest that the specific sequence of the duplex stem in SL1 is important for efficient replication of HCV RNA. Structures possessing duplex stems of comparable stability but different primary nucleotide sequence cannot functionally substitute for SL1, even when the nucleotide sequence is kept constant within either the apical or basal half of the stem as well as within the loop. Despite this, we found that it was possible to select G418resistant cells following transfection with the SL1-A/AA mutant RNA at a very low frequency. This indicates that this particular mutant retains a very low level of replication competence. Interestingly, none of the other mutants shown in Figure 5 possessed such a pseudo-lethal phenotype, including the single block substitution SL1-A and SL1AA mutants. This provides support for the existence of the duplex stem, and for a specific requirement for the structure in replication of the RNA. We discuss the characterization of replicon RNAs recovered from G418-resistant cell lines selected following transfection with the pseudo-lethal SL1A/AA mutant in a subsequent section.

\section{Point mutations near the ends of the duplex stem block replication of HCV RNA}

To better understand why RNAs containing complementary block substitutions within the duplex stem fail to replicate efficiently (Fig. 5B), we introduced a series of point mutations into the sequences forming the stem (Fig. 6A). Computer-assisted structure analysis predicted that point mutations created within the central region of the stem are likely to induce only minor local structural changes (e.g., mutations at nt 10,13,15, and their putative base-pairing partners, nucleotides 33, 35, and 38; Fig. 6A). These mutations had relatively little effect on the efficiency of RNA replication in the transient transfection assay, reducing SEAP expression by no more than $50 \%$ from that produced following transfection of the parental Ntat2ANeo(SI) transcript (for the sake of clarity, these results are presented in a 
A

\begin{tabular}{|c|c|c|}
\hline$\rightarrow$ & Ntat2ANeo(SI) & $\begin{array}{l}\text { LGCAUGACUGCAGAGAGGCUGA } \\
\text { 3' gaucuGUACUGACGUCUCUCCGG UCA }\end{array}$ \\
\hline & SL1-AA & $\begin{array}{r}\text { GCAUGACUGCAGAGAGGCUGA } \\
\text { gaucuGCAUGACUGCUCUCUCCGG UC } \\
U\end{array}$ \\
\hline & SL1-A & $\begin{array}{r}\text { CGUACUGACG }_{A G A G A G G C U G A} \cup \\
\text { gaucUGUACUGACGUCUCUCCGGUC } \\
A\end{array}$ \\
\hline & SL1-A/AA & $\begin{array}{r}\text { CGUACUGACGAGAGAGGCU }{ }^{G A} U \\
\text { gaucuGCAUGACUGCUCUCUCCCGGUC }\end{array}$ \\
\hline & SL1-BB & $\begin{array}{r}\text { GCAUGACUGCAGAGAGGCUGA }{ }^{\mathrm{U}} \mathrm{U}_{\mathrm{A}} \\
\text { gaucUGUACUGAGGAGAGGUUC }\end{array}$ \\
\hline & SL1-B & $\begin{array}{r}\text { GCAUGACUGCUCUCUCCGAGA } U \\
\text { gaucUGUACUGACGUCUCUCCGG UCA }\end{array}$ \\
\hline & SL1-B/BB & $\begin{array}{r}\text { GCAUGACUGCUCUCUCCGAGA } U \\
\text { gaucUGUACUGACGAGAGAGGCU U }{ }_{C}^{A}\end{array}$ \\
\hline & $\Delta \mathrm{GDD}$ & $\begin{array}{r}\text { GCAUGACUGCAGAGAGGCUGA }{ }^{G A} \\
\text { gaucUGUACUGACGUCUCUCCGG UC }\end{array}$ \\
\hline
\end{tabular}

B

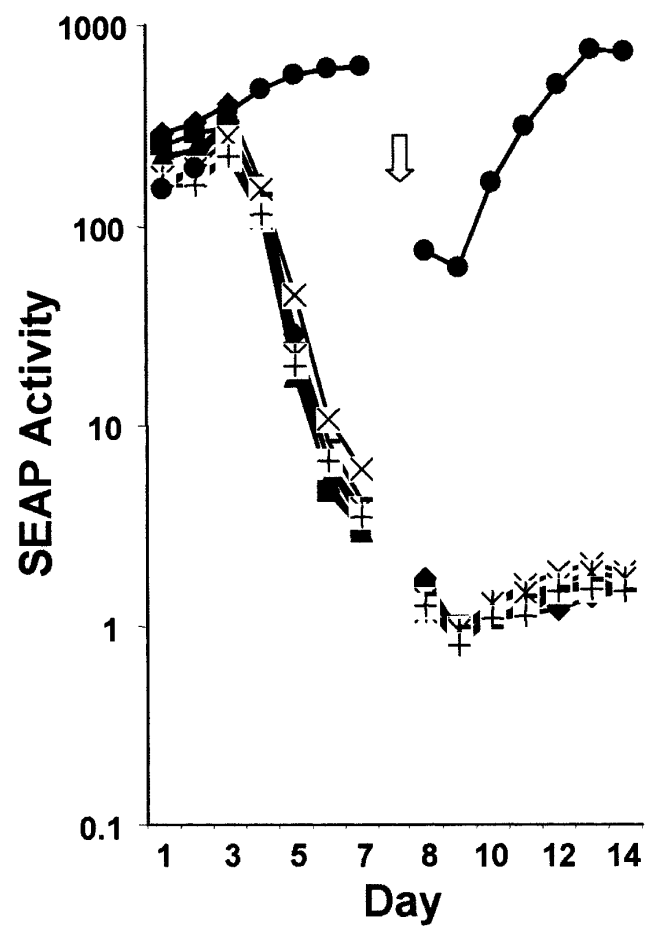

FIGURE 5. Transient transfection of En5-3 cells with Ntat2ANeo(SI) and related mutants containing block nucleotide substitutions within the putative duplex stem of the SL1 stem-loop. (A) Schematic showing the highlighted block mutations within the loop segment. (B) SEAP activity present in supernatant culture fluids collected at 24-h intervals following transfection of En5-3 cells with Ntat2ANeo(SI) (filled circles) and related mutant RNAs containing block substitutions within the lower half of the stem, SL1-AA (filled triangles), SL-A (filled squares), SL1-A/AA (multiplication sign), SL1-BB (plus sign), SL1-B (asterisk), or SL1-B/BB (minus sign). Note that SL1-A/AA and SL1-B/BB contain complementary block substitutions that were predicted to preserve base pairing within the putative duplex stem. Results are also shown following transfection of Ntat2ANeo(SI) RNA containing the $\triangle$ GDD mutation that is lethal for replication (filled diamond). The transfected cells were passaged after collection of the supernatant fluid at day 7 (open arrow).

tabular fashion in Fig. 6B). Because each of the single point mutations replicated so well, it was not possible to draw conclusions about the existence of the duplex stem from the results obtained with single, versus dual, complementary mutations at these positions. Substitutions created at nt 7A and $30 \mathrm{U}$, both of which are predicted to be unpaired and looping out of the duplex (Fig. 6A), also failed to substantially impair replication of Ntat2ANeo(SI) RNA (Fig. 6B). This indicates that the impaired replication capacities of the SL1-A/AA and SL1-B/BB mutants (Fig. 5) cannot be related to the substitutions at these two nucleotide positions.

Interestingly, however, a very different result was obtained with point mutations introduced at either end of the duplex stem. The 19C and 28G mutations are located at the penultimate positions in the stem, adjacent to the predicted G-U closing base pair at the bottom of the loop in SL1 (Fig. $6 \mathrm{~A})$. Either mutation completely abrogated replication of the subgenomic RNA in En5-3 cells (Fig. 6B). Importantly, both substitutions also had a significant effect on the structure of the apical end of the hairpin as predicted by
MFOLD, as well as the structure of the loop (Fig. 6C). Strikingly, a combination of these two substitutions, which restored the predicted SL1 structure, also restored replication to near normal levels. These latter results provide strong evidence for the existence of the predicted 19G-28C base pair. They suggest that base pairing in this region of the predicted stem is important for replication of the viral RNA, presumably by facilitating recognition of the $3^{\prime}$ terminus of the RNA by the viral replicase complex. Taken together with the results shown in Figure 3, the results suggest that structure in the region of the junction of the loop and the duplex stem is critically important in these processes.

Point mutations at the base of the hairpin also had a dramatic effect on replication of the RNA. The $2 \mathrm{C}$ and $45 \mathrm{G}$ substitutions, located at penultimate positions near the base of the predicted stem (Fig. 6A), both completely blocked RNA replication in the transient transfection assay (Fig. $6 \mathrm{~B})$. However, in this case, the combination of these compensatory mutations failed to restore an efficient replication phenotype to the RNA, even though the combination of the 
A

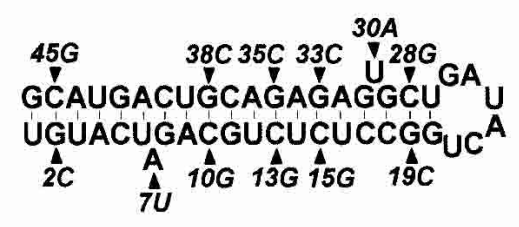

C

$19 \mathrm{C}$

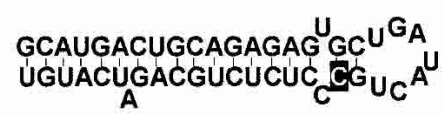

$28 G$

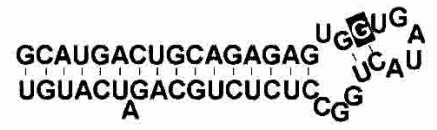

19C-28G
B

\begin{tabular}{|l|c|}
\hline Transcript & SEAP (\%) \\
\hline 2C & $1.7 \pm 0.5$ \\
45G & $1.2 \pm 0.4$ \\
2C-45G & $1.5 \pm 0.7$ \\
\hline $10 G$ & $57 \pm 13$ \\
38C & $32 \pm 4$ \\
10G-38C & $72 \pm 4$ \\
\hline 13G & $44 \pm 4$ \\
35C & $57 \pm 14$ \\
13G-35C & $66 \pm 16$ \\
\hline 15G & $34 \pm 4$ \\
33C & $32 \pm 6$ \\
15G-33C & $37 \pm 4$ \\
\hline 19C & $1.9 \pm 1.0$ \\
28G & $1.7 \pm 1.3$ \\
19C-28G & $37 \pm 9$ \\
\hline 7U & $138 \pm 37$ \\
30A & $44 \pm 9$ \\
7U-30A & $92 \pm 20$ \\
\hline Ntat2ANeo(SI) & 100 \\
$\Delta G D D$ & $1 \pm 0.4$ \\
\hline
\end{tabular}

FIGURE 6. Summary of results obtained following transfection of En5-3 cells with Ntat2ANeo(SI) and related mutants containing single or double nucleotide substitutions within the duplex stem of SL1. (A) Schematic showing the predicted SL1 structure and location of nucleotide substitutions. (B) Table showing SEAP activities following transient transfection with RNAs containing the indicated single and double nucleotide substitutions. SEAP activities are shown as the percentage of SEAP activity induced by the Ntat2ANeo(SI) replicon containing the wild-type $3^{\prime}$ NTR sequence. Average SEAP values were obtained in two independent experiments at days 10,11 , and 12 after transfection ( 3,4 , and 5 days after splitting of the cells). Note that mutants highlighted in boldface type in the table contain potentially compensatory nucleotide substitutions that are predicted to conserve structure. (C) MFOLD-predicted structures of the mutants 19C, 28G, and 19C-28G.

mutations restored the predicted structure at the base of the hairpin. These data suggest that the specific nucleotide sequence at the base of the hairpin is also critical for recognition by the replicase and/or initiation of negative-strand, viral RNA synthesis. This was a surprising finding, given the pseudo-lethal nature of the SL1-A/AA mutant (Fig. 5A) described above, and the fact that it retained at least a low level capacity for replication.

\section{Characterization of replicon RNAs recovered from cells transfected with transcripts containing pseudo-lethal mutations at the base of the hairpin}

Although the single and double $2 \mathrm{C}, 45 \mathrm{G}$, and $2 \mathrm{C}-45 \mathrm{G}$ substitution mutants did not induce SEAP levels indicative of replication in the transient transfection assay (Fig. 6), it was possible to select G418-resistant cell clones following transfection with the $2 \mathrm{C}$ mutant. Colony outgrowth occurred only at a very low frequency $\left(\sim 10\right.$ colonies per $10^{6}$ transfected cells), indicating that this mutant RNA retains a level of replication activity that is at least a thousandfold less than that of the parental Ntat2ANeo(SI) RNA. Importantly, the 2C-45G mutant was completely lethal, and did not give rise to G418-resistant cell colonies at any detectable frequency. To determine whether the replication of the $2 \mathrm{C}$ mutant was associated with reversion of the mutation, replicon RNAs were recovered from G418-resistant cells transduced with $2 \mathrm{C}$ and their $3^{\prime}$ terminal sequences determined following amplification of cDNA by RT-PCR. These results showed that the RNA had reverted to the parental $G$ sequence at the second base position from the $3^{\prime}$ end of the genome (data not shown). This confirms the importance of the wild-type $2 \mathrm{G}$ base for replication of the viral RNA. The failure of the $2 \mathrm{C}-45 \mathrm{G}$ mutant to replicate even at low levels (Fig. 6) may reflect a requirement that the $2 \mathrm{G}$ nucleotide be base paired (see below). The 45G single mutant did not give rise to G418resistant colonies.

The SL1-A/AA mutant (Fig. 5A) also had a pseudo-lethal phenotype, as G418-resistant colonies could be selected following transfection of this RNA despite little apparent difference in the levels of SEAP expression induced by this RNA and the replication-incompetent $\Delta \mathrm{GDD}$ mutant in the transient replication assay (Fig. 5B). These G418resistant cells were of particular interest because the entire basal half of the SL1 stem had been inverted in sequence by large block substitutions in this mutant (Fig. 5A). Northern analysis confirmed the presence of the replicon RNA in clonally isolated G418-resistant cell lines obtained following transfection with the SL1-A/AA RNA (Fig. 7A, lanes 3,4,5), although the abundance of the replicon was substantially lower than in either of two G418-resistant cell lines selected following transfection with RNA containing the intact 3'NTR, Ntat2ANeo(RG) (Fig. 7A, lanes 2,6; Yi and Lemon 2002; Yi et al. 2002). In one of three independent G418resistant SL1-A/AA cell lines studied, the abundance of the replicon RNA was at the limits of detection by northern analysis (Fig. 7A, lane 4).

Sequencing of the $5^{\prime}$ and $3^{\prime}$ termini of the replicon RNAs present in cell lines transduced with SL1-A/AA demonstrated the presence of the block substitutions in the stem of SL1. There were no changes in the mutated nontranslated RNA segments except for, remarkably, the presence of an additional $3^{\prime}$ terminal U (Fig. 7B). This additional nucleotide was present in RNAs recovered from each of the three independent SL1-A/AA replicon-bearing cell lines shown in Figure 7A. The SL1-A/AA transcripts, like all the RNAs transfected into En5-3 cells in the preceding experiments, were derived by runoff transcription from plasmid DNAs that had been linearized by digestion with Xbal (see Materials and Methods; Ikeda et al. 2002). Because of the pro- 


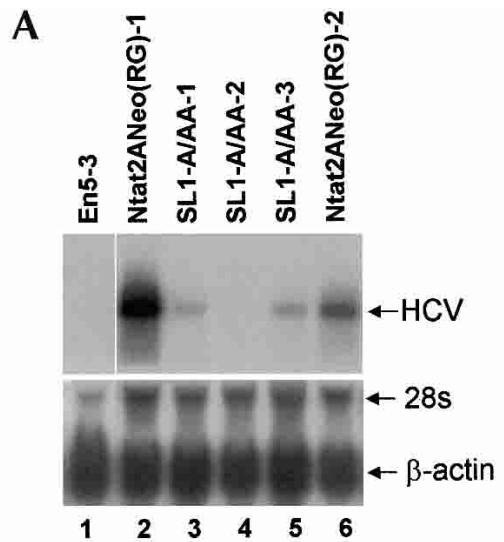

B

Ntat2ANeo(SI)
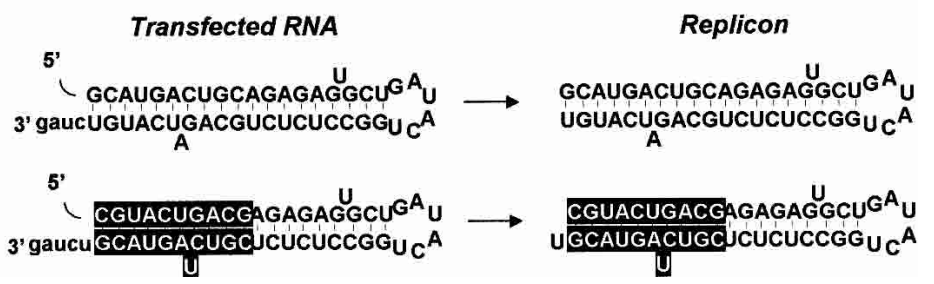

FIGURE 7. Analysis of replicating RNAs within stable, G418-resistant cell lines. (A) Northern analysis of HCV RNA present in G418-resistant cells lines selected following transfection with replicon RNAs: (lane 1) normal En53 cells, (lanes 2, 6) cell lines selected following transfection with Ntat2ANeo(RG) RNA (Ntat2ANeo with a cell culture-adaptive Arg to Gly substitution in NS5B; Lohmann et al. 2001; Ikeda et al. 2002), (lanes 3-5) three independent cell lines selected following transfection with the SL1-A/AA mutant (see Fig. 6). The lower panel shows hybridization with a probe specific for $\beta$-actin as a loading control. (B) $3^{\prime}$ terminal sequences of the transfected RNAs, and the replicon RNAs present within the G418-resistant cell lines that were determined following RT-PCR amplification. The SL1 structure is shown as it is predicted to fold in the parental sequence; mutated bases within the HCV sequence are highlighted, and bases shown in lowercase are exogenous to the HCV sequence.

truding $5^{\prime}$ end generated by this restriction enzyme, these RNAs contain four exogenous nucleotides downstream of the $3^{\prime}$ terminus of the HCV sequence. We have previously shown that these exogenous nucleotides are removed following transfection and replication of the RNA, and that the nucleotide sequence of the extreme 3 ' end of replicon RNAs present in stable G418-resistant cell clones is identical to that of the virus (Yi and Lemon 2002). In constructing the SL1-AA and SL1-A/AA plasmids (Fig. 5A), it was necessary to add an additional $\mathrm{T}$ downstream from the $3^{\prime}$ terminus of the mutated viral sequence to maintain the $\mathrm{XbaI}$ restriction site required for linearization of the DNA prior to transcription of the RNA. This increased the number of nonHCV bases included at the $3^{\prime}$ end of these RNA transcripts from four to five (Fig. 7B). The additional $\mathrm{U}$ at the $3^{\prime}$ terminus of the SL1-A/AA replicons recovered from the G418-resistant cells is likely to have been derived by retention of the extra $U$ that was present in these transcripts due to the need to maintain the restriction endonuclease recognition site in the plasmid DNA.

The retention of this $\mathrm{U}$ in the replicating RNAs suggests the possibility that the $3^{\prime}$ terminal $U$ residue may also play an important role in recognition of the RNA by the repli- case. It is important to note that the retention of this exogenous $\mathrm{U}$ preserved the native $3^{\prime}$ terminal GU dinucleotide sequence in HCV RNA, and that the G residue in the second base position from the $3^{\prime}$ end is base paired in these replication-competent RNAs (see above).

\section{$U$ is the preferred $3^{\prime}$ terminal nucleotide}

As described above, exogenous nucleotides that are present at the $3^{\prime}$ end of synthetic replicon transcripts are lost from the RNA as it replicates ( $\mathrm{Yi}$ and Lemon 2002), except in the case of the pseudo-lethal SL1-A/AA mutant, where the most $5^{\prime}$ of these nucleotides, a $\mathrm{U}$, was retained (Fig. 7B). To ascertain the extent to which these exogenous nucleotides influence the initial replication of the RNA following transfection, we modified the Ntat2ANeo(SI) plasmid by placing a $B c i V I$ restriction recognition site downstream of the $\mathrm{XbaI}$ restriction site (Fig. 8A). The presence of these two restriction endonuclease recognition sites allowed for the production of two different classes of RNA transcripts, one (produced from BciVI-digested plasmid DNA) having a $3^{\prime}$ terminus identical to that of HCV RNA, and the other (produced from XbaI-digested DNA) that retained the exogenous nucleotides downstream from the HCV sequence. Figure $8 \mathrm{~B}$ shows SEAP expression levels following transfection of En5-3 cells with a BciVI runoff transcript ending at the native $3^{\prime}$ terminal $\mathrm{U}$ and an $\mathrm{XbaI}$ NtatNeo2A(SI) runoff containing four exogenous $3^{\prime}$ bases. These results demonstrated that the elimination of the exogenous nonviral nucleotides from the Ntat2ANeo(SI) transcripts leads to an approximate doubling of the expressed SEAP activity. Following transfection of En5-3 cells, the first increase in SEAP activity occurred approximately one day earlier (3 days) with the BCiVI transcript than with XbaI transcript (4 days).

Having shown that an RNA with the precise $3^{\prime}$ terminal sequence of HCV had a moderately improved capacity for replication, we next constructed a series of Ntat2ANeo(SI) mutants with the $B C i \mathrm{Vi}$ restriction site in which the $3^{\prime}$ terminal $\mathrm{U}$ of the HCV sequence was replaced with $\mathrm{A}, \mathrm{C}$, or G. The RNAs produced from these plasmids have the exact 3' terminus of HCV RNA with the exception that the nucleotide composition is varied at the extreme $3^{\prime}$ terminal position. Figure 8C depicts an experiment in which En5-3 cells were transfected with these RNAs. These results demonstrated a clear difference in the efficiency of replication of 
A

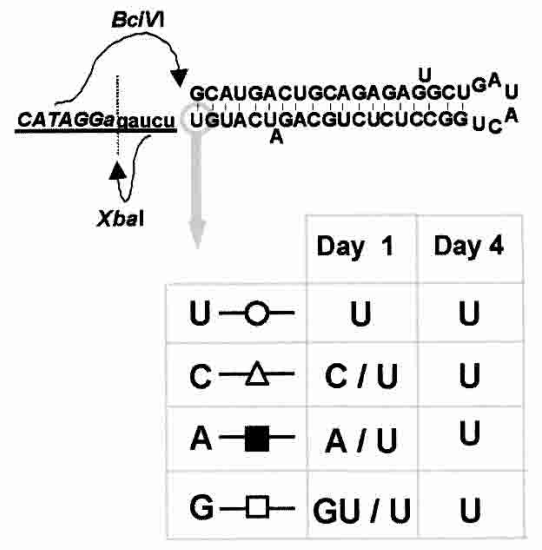

B

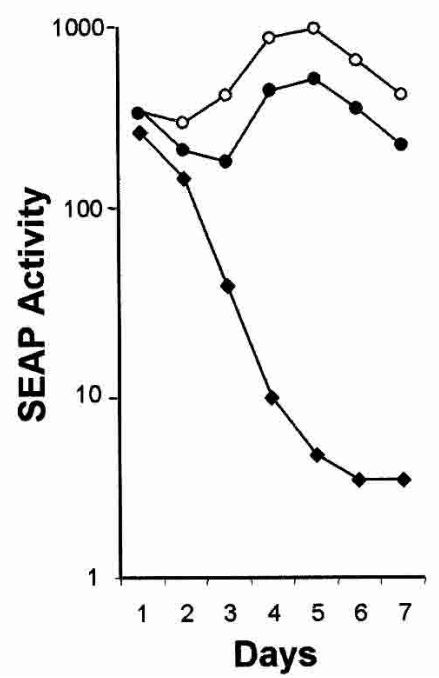

C

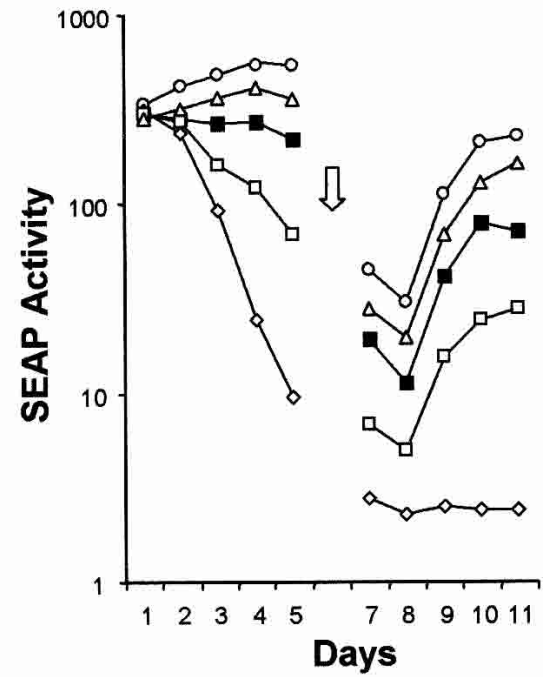

FIGURE 8. Importance of the $3^{\prime}$ terminal U nucleotide to replication of subgenomic HCV RNA. (A) Schematic showing location of the XbaI and $B c i$ VI restriction endonuclease recognition sites placed downstream from the HCV sequence in the plasmid version of Ntat2ANeo(SI) (pU-BciVI) used for these experiments. Runoff transcripts prepared after BciVI restriction have the exact $3^{\prime}$ terminal sequence of HCV genomic RNA. The lower half of the panel shows the 3' nucleotide sequence of RNAs present in En5-3 cells 1 and 4 days after transfection with transcripts containing different $3^{\prime}$ terminal nucleotides (see C). Note that at day 1 post-transfection, the $3^{\prime} \mathrm{G}$ mutant was no longer detectable, and had been replaced by a 3' $\mathrm{U}$ revertant or a second revertant that had an additional 3' $\mathrm{U}$ residue downstream from the G substitution. By day 4, reversion was complete for all three mutants. (B) SEAP expression following transient transfection of En5-3 cells with Ntat2ANeo(SI) RNA prepared by XbaI runoff transcription, and thus containing 4 exogenous nucleotides at the $3^{\prime}$ end of the transcript (filled circles), and Ntat2ANeo(SI) BciVI transcripts that terminate with the precise $3^{\prime}$ end of HCV RNA (open circles). Also shown is SEAP expression following transfection with the replication-incompetent $\triangle$ GDD mutant (filled diamonds). (C) SEAP expression following transient transfection of En5-3 cells with Ntat2ANeo(SI) BciVI runoff transcripts terminating in the authentic $3^{\prime}$ terminal U residue (open circles), and related mutant RNAs with $3^{\prime}$ terminal C (open triangles), A (filled squares), and G residues (open squares). The 3' terminal sequences of the transfected RNAs were determined 1 and 4 days after transfection, with the results shown in A. In this experiment, the cells were passaged 6 days after transfection (open arrow). Also shown is SEAP expression following transfection with the replication-incompetent (filled diamonds) $\Delta$ GDD mutant.

these RNAs that was reproducible in other experiments. RNA transcripts with the native $3^{\prime}$ terminal $\mathrm{U}$ replicated more efficiently than the other RNAs. The order of replication efficiency was $\mathrm{U}$ first, followed by $\mathrm{C}$, A, and then G, with the $\mathrm{G}$ mutant inducing only about $10 \%$ of the SEAP activity produced by the wild-type $3^{\prime}$ terminal $\mathrm{U}$ (Fig. 8C).

To show that the variation in the replication efficiency of these mutants was not due to the $3^{\prime}$ terminal nucleotide influencing the stability of RNA, we created a deletion mutation within the NS5B sequence in each of these constructs. Because these $\triangle$ GDD mutants are incapable of RNA replication, any induction of SEAP secretion is due entirely to translation of the input transfected RNA. Therefore, under these conditions, the kinetics of SEAP expression represent a measure of the stability of the transfected RNA (Yi et al. 2002). We compared the levels of SEAP expressed by cells transfected with these double mutants with that expressed by cells transfected with RNAs containing only the $3^{\prime}$ nucleotide substitution. There was a clear difference in the levels of SEAP induced by the replication-competent single mutants with different $3^{\prime}$ terminal nucleotides that was evident within 3 days of transfection (Fig. 9A). However, the 3' nucleotide substitution had no influence on the kinetics of expression of SEAP following transfection of the $\triangle \mathrm{GDD}$ double mutants (Fig. 9B). This indicates that the difference in replication efficiency was not due to variation in the stability of the RNA. We were also unable to detect consistent differences in the stabilities of these RNAs by measuring RNA abundances with a real-time RT-PCR assay following transfection of the mutants (data not shown). Because tat is expressed from these replicon RNAs under the translational control of the HCV IRES, the fact that the levels of SEAP expression were indistinguishable $24 \mathrm{~h}$ after transfection of the different RNAs (Fig. 9) also indicates that the variance in replication efficiency was not associated with significant differences in the translational activity of the HCV IRES.

Figure 8C shows that the rate of increase in SEAP activity was similar with all four terminal nucleotide variants 7 days after transfection, following passage of the transfected cells, although the absolute levels of SEAP were quite different. This contrasts with the different rates of increase in SEAP activity that were evident in the first few days following transfection (Figs. 8C, 9A). Because we have previously shown that the levels of SEAP produced by transfected cells are highly correlated with intracellular replicon abundance 
A
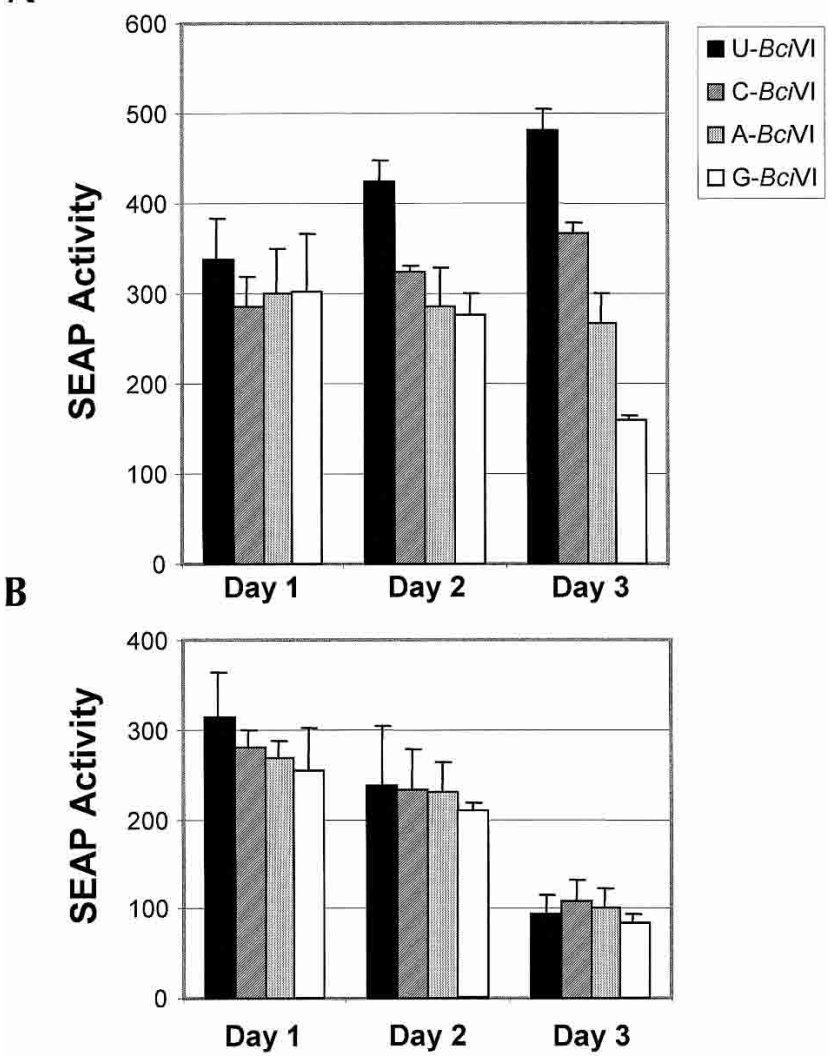

FIGURE 9. (A) SEAP activity present in supernatant culture fluids collected at 24-h intervals following transfection of En5-3 cells with $B c i$ I runoff transcripts containing the precise $3^{\prime}$ terminus of the genomic RNA of HCV with the exception of the first base position at the $3^{\prime}$ end of the RNA that varied as shown in the figure: $U$ (solid bar), C (striped bar), A (stippled bar), and G (open bar). (B) Results from paired transfection experiments with $\triangle$ GDD mutants created within the background of each of the transcripts shown in $A$. In $A$, a difference in the replication capacity of these RNAs is evident by 3 days after transfection. In $B$, however, there is no difference in the level of SEAP expression over this period of time, indicating that there are no significant differences in the stability or translational activity of these RNAs. Error bars represent the range of duplicate assays on each day. Solid bars represent U-BciVI, hatched bars represent C-BciVI, stippled bars represent A-BciVI, and open bars represent G-BciVI.

(Yi et al. 2002), this suggests that the mutants had regained a level of replication efficiency similar to that of the parental RNA with a $3^{\prime}$ terminal $U$ by 8 days post-transfection. To determine whether this apparent change in replication capacity was associated with reversion of the $3^{\prime}$ terminal nucleotide substitutions to U, we isolated RNA 24 and $96 \mathrm{~h}$ following transfection of the mutants into cells and determined the $3^{\prime}$ terminal nucleotide sequence of the RNA as described in Materials and Methods. These results indicated that there was rapid reversion of the mutated $3^{\prime}$ terminal nucleotides to $\mathrm{U}$. RNAs containing a $3^{\prime}$ terminal $\mathrm{U}$ were present as mixtures with the transfected RNA sequence as early as $24 \mathrm{~h}$ after transfection, with $\mathrm{U}$ being the dominant sequence at $96 \mathrm{~h}$ after transfection of each RNA (results summarized in Fig. 8A). These results confirm that the
HCV RNA replicase possesses a strong preference for $\mathrm{U}$ as the $3^{\prime}$ terminal residue of the genomic RNA.

\section{DISCUSSION}

Although previous studies have shown that the 3' nontranslated sequence of the genomic RNA of HCV is essential for replication of the virus (Yanagi et al. 1999; Kolykhalov et al. 2000; Friebe and Bartenschlager 2002; Yi and Lemon 2002), there has been little understanding of how these sequences contribute specifically to the viral life cycle. Here, we present an extensive mutational analysis of the 46-nt sequence that has been suggested to form a hairpin structure, SL1, at the extreme 3' end of the RNA (Kolykhalov et al. 1996; Tanaka et al. 1996; Blight and Rice 1997; Ito and Lai 1997). The results of these studies provide strong functional evidence for the existence of this structure and for an essential role of the structure in replication of the viral RNA. The two compensatory mutations present in the mutant 19C-28G were compatible with continued replication of a subgenomic replicon, whereas either of these mutations was lethal to replication when introduced individually (Fig. 6). In addition, the dual SL1-A/AA mutant, which contains compensatory block substitutions in the lower half of the duplex stem of SL1, was able to transduce the selection of G418resistant colonies, whereas individual SL1-A or SL1-AA mutants did not have this capacity (Figs. 5, 7). These data provide strong functional evidence for a structure that up until now has been supported only by computer modeling of the RNA sequence, and by physical mapping of ribonuclease cleavage sites and sites of chemical modification within synthetic RNA.

The fact that point mutations within the central region of the duplex stem (at nucleotides 10, 13, and 15 and 33, 35, and 38 , from the $3^{\prime}$ end of the RNA) had only small effects on replication (Fig. 8), coupled with the ability of the SL1A/AA revertants to replicate in En5-3 cells (Fig. 7), suggests that there is relatively little requirement for specific nucleotide sequence within this part of the hairpin structure, as long as the structure is maintained. The lack of effect of the single base mutations also suggests that it is not necessary to have a perfect duplex structure in this part of the stem. In contrast, at either end of the stem, specific base sequences and/or structure appear to be much more important. It was not possible to recover G418-resistant cells following transfection of the double SL1-B/BB (Fig. 5A) mutant. RNA replication was also abrogated by individual $19 \mathrm{C}$ and $28 \mathrm{G}$ mutations at the penultimate base positions near the apex of the stem (Fig. 6), or 21A, 22G, and 26C mutations adjacent to the stem but within the loop sequence (Fig. 3). In contrast, the distal nucleotides within the loop (Fig. 3, 23A, $24 \mathrm{U}, 25 \mathrm{~A}$ ) could be altered without loss of replication competence.

These results are consistent with the location of natural nucleotide substitutions that have been found to be present 
within the SL1 sequence of other strains of HCV. Although there is only limited diversity within this highly conserved sequence, an analysis of GenBank submissions shows that certain bases are absolutely conserved, including the $21 \mathrm{U}$, 22C, and 26G bases, as well as $19 \mathrm{G}$ and 28C (Fig. 10). Base substitutions that are present in other strains are generally located within the central part of the duplex stem, particularly near 7A and 30U, which are looped out of the duplex in the dominant sequence, or at the apex of the loop. It is noteworthy that the sequence producing the most stable predicted SL1 structure is that which is present in the replicon we studied (Fig. 10), and which constitutes the large majority of sequences present in GenBank.

These observations lead us to suggest that the structure present at the junction of the stem and the loop is critically important for replication, possibly because it plays an essential role in recognition of the $3^{\prime}$ end of the RNA by the viral replicase complex. The critical nature of this structure

A AF139594
HCV-N
-26.5 kcal GCAUGACUGCAGAGAGGCU GA
UGUACUGACGUCUCUCCGG
A

B

D67095
$-25.2 \mathrm{kcal}$

AB047641
HCV JCH-2
$-23.8 \mathrm{kcal}$

AF13959

$-22.2 \mathrm{kcal}$

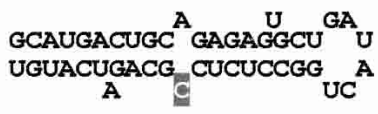

AJ132997 HCV-AD78P1 $-21.7 \mathrm{kcal}$

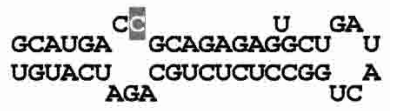

D85021

$-20.9 \mathrm{kcal}$
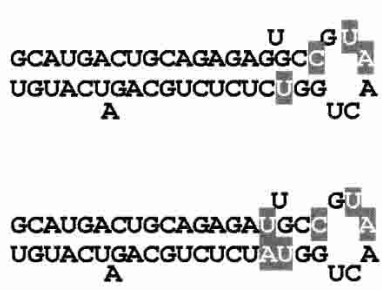

$\mathrm{A}$

西

is further supported by reversion of the $21 \mathrm{G}$ and $26 \mathrm{U}$ mutations at the base of the loop in replicating RNAs that were present in the G418-resistant cell lines selected following transfection with the $21 \mathrm{G}-26 \mathrm{U}$ mutant (Fig. 4). It is interesting that there were second-site mutations in some of these revertant RNAs, including a base change within the putative loop sequence of a second stem-loop (SL2) that has been proposed to form just upstream of SL1 (Fig. 4; Kolykhalov et al. 1996; Blight and Rice 1997). The presence of these additional mutations raises the possibility that the repair process involved the evolution of intermediate mutants, with replication capacity greater than the $21 \mathrm{G}-26 \mathrm{U}$ mutant but less than the parental sequence, and that these sequences may thus be involved in complex tertiary interactions that have yet to be deduced, but that are important for RNA replication.

We also found that the bases present at the $3^{\prime}$ terminus of the RNA had an important influence on the replication capacity of subgenomic RNAs. The wild-type $U$ was strongly preferred at the $3^{\prime}$ end of the RNA (Fig. 8). This preference cannot be attributed simply to the need to maintain base pairing in the stem. Although a $\mathrm{C}$ at this position would be predicted to form a more stable base pair with G46, RNA containing a $3^{\prime}$ terminal C substitution replicated significantly less efficiently than RNA possessing a $3^{\prime}$ terminal U (Fig. 8C). Moreover, the $3^{\prime}$ terminal $\mathrm{C}$ was rapidly replaced with $\mathrm{U}$ as the RNA replicated in the transient assay (Fig. 8A). The data also suggest a preference for $\mathrm{G}$ at the second base position from the $3^{\prime}$ end. As shown in Figure 6, a mutant in which $2 \mathrm{G}$ was substituted with $\mathrm{C}$ failed to replicate in the transient assay, even when a compensatory $\mathrm{G}$ mutation at $45 \mathrm{C}$ was introduced to maintain base pairing. The inability of the dual $2 \mathrm{C}-45 \mathrm{G}$ mutant to replicate cannot be attributed to a need to maintain a $\mathrm{C}$ at the 45 th nucleotide from the $3^{\prime}$ end, however, because revertant RNAs selected from the pseudo-lethal SL1-A/AA mutant were capable of relatively efficient replication despite substitutions throughout this part of the stem, including the 45G substitution itself (Fig. 7). These data thus support the notion that there is a strong preference for the $5^{\prime}$... GU-3' dinucleotide sequence that normally resides at the $3^{\prime}$ end of HCV RNA. It is interesting to note that M. Nomaguchi, M. Ackermann, S. You, and R. Padmanbhan (in prep.) have recently shown that the dengue virus replicase also has a strong preference for a $3^{\prime}$ terminal $U$ in the RNA template, suggesting that this preference may be broadly conserved among the Flaviviridae.

Shim et al. (2002) reported recently that purified recombinant HCV NS5B polymerase could initiate RNA transcription de novo in an in vitro reaction at the first, second, or third bases from the $3^{\prime}$ end of short oligoribonucleotide templates. Using template oligoribonucleotides that were identical to the $3^{\prime}$ terminus of HCV RNA except at the most $3^{\prime}$ base, they found that the efficiency with which the polymerase initiated transcription at the $3^{\prime}$ terminus was great- 
est when the terminal nucleotide was $U$, and progressively less when it was $\mathrm{G}, \mathrm{A}$, or $\mathrm{C}$. These results agree with the preference of the HCV polymerase for a $3^{\prime}$ terminal $U$, but they differ from our results in the order of the relative efficiencies of other bases at this location. In the more complex in vivo replicon system that we studied, the order was $\mathrm{U}, \mathrm{C}, \mathrm{A}$, and $\mathrm{G}$. It is noteworthy that the $3^{\prime}$ terminal bases are $5^{\prime}-\ldots \mathrm{GU}-3^{\prime}$ in all HCV genomic RNA sequences reported to date, whereas the predicted $3^{\prime}$ terminal bases of the negative strand intermediate RNA are $5^{\prime}-\ldots$ GC- $3^{\prime}$.

The difference between the order of the efficiency of transcriptional initiation with various $3^{\prime}$ terminating bases in vitro (Shim et al. 2002) and in vivo, as reported here, may reflect the incomplete nature of the in vitro reaction studied by the former group. Nonstructural proteins other than NS5B were not present in the reaction mix, although they are likely to be part of the native replicase complex (Egger et al. 2002). Moreover, the C-terminal residues had been removed from the recombinant NS5B polymerase used in the in vitro reaction to enhance its solubility (Shim et al. 2002), and RNA transcription did not take place at the surface of intracellular membranes as it is likely to do in vivo (Egger et al. 2002). The incomplete nature of the in vitro reaction may also explain why transcription was abortive in this system, leading to few reaction products beyond dinucleotides (Shim et al. 2002). Despite these differences, it is important to note that results from both the in vivo and in vitro systems indicate that the $3^{\prime}$ terminal nucleotide sequence of the template is very important to the viral replicase.

The results presented here provide strong evidence that the SL1 stem-loop plays an important role in replication of HCV RNA, most likely by facilitating the recognition of the $3^{\prime}$ end of the genomic RNA by the viral replicase complex. The data suggest that two subdomains located at opposing ends of the structure are particularly critical for this process (the region at the junction of the stem and the loop, and the 3 ' terminal nucleotides), whereas the requirements for the intervening duplex stem are less stringent (Fig. 10). The molecular basis for these requirements remains unknown. It is possible that the $3^{\prime}$ terminal bases interact in a specific fashion with the active site of the replicase in order to achieve the initiation of transcription of negative-strand RNA at the $3^{\prime}$ end of the genome. This requires further study, but it is an attractive hypothesis. If it is correct, then the apical part of the stem-loop, specifically the structure at the junction of the duplex stem and the loop, may be involved in RNA-RNA or RNA-protein interactions that facilitate this process.

\section{MATERIALS AND METHODS}

\section{Cells}

En5-3 cells are a clonal cell line derived from Huh7 cells by stable transformation with the plasmid pLTR-SEAP (Yi et al. 2002).
These cells were cultured in Dulbecco's modified Eagle's medium (GIBCO BRL) supplemented with $10 \%$ fetal calf serum, $2 \mu \mathrm{g} / \mathrm{ml}$ blasticidin (Invitrogen), penicillin, and streptomycin. Cell lines were passaged once or twice per week. We used $250 \mu \mathrm{g} / \mathrm{ml}$ of G418 to select colonies from Huh-7 cells transfected with replicon RNAs containing $3^{\prime}$ NTR mutations.

\section{Plasmids}

The plasmid pNtat2ANeo(SI) contains a T7 transcriptional unit encoding a replication-competent, dicistronic subgenomic HCV RNA that expresses the human immunodeficiency virus (HIV) tat protein from its upstream cistron (Fig. 1; Yi et al. 2002). A subclone constructed from this plasmid, $\mathrm{pHCV}-\mathrm{N} \Delta \mathrm{Cla}$, was used to generate a series of mutants with nucleotide substitutions within the $3^{\prime}$ terminal $46 \mathrm{nt}$ of the HCV sequence (putative SL1 domain) by PCR mutagenesis (Fig. 3, BLoop, 21A, 22G, 23U, 24A, 25U, 26C mutants; Fig. 4, 26A, 26U, 21G-26U; Fig. 5, SL1-AA, SL1-BB, SL1-B; and Fig. 6, 2C, 7U, 10G, 15G, 13G, 19C, 28G ), as described previously (Yi and Lemon 2002). Quick-Change (Stratagene) mutagenesis was used for construction of other SL1 mutants (Fig. 5, SL1-A, SL1-A/AA, SL1-B/BB; and Fig. 6, 19C-28G, 30A, 33C, 35C, $38 \mathrm{C}, 45 \mathrm{G}$ ) using the template $\mathrm{pHCV}-\mathrm{N} \Delta \mathrm{Cla}$ (Yi and Lemon 2002). The mutants 2C-45G, 10G-38C, and 13G-35C were constructed by PCR mutagenesis using p45G, p38C, and p35C plasmid DNAs as template, respectively. To construct p15G-33C, Quick-Change mutagenesis was carried out on a p15G template using the $33 \mathrm{C}$ primer set. The construction of $\mathrm{p} \Delta \mathrm{SL} 1 \mathrm{~h}$ has been described elsewhere (Yi and Lemon 2002). The resulting products were verified by sequencing the entire $3^{\prime}$ NTR region, with the $3^{\prime}$ NTR fragments subsequently ligated into pNtat2Aneo(SI) at the $\mathrm{ClaI}$ and $\mathrm{XbaI}$ sites.

The plasmid $\mathrm{pU}-\mathrm{BciVI}$ is a modified version of $\mathrm{pNtat} 2 \mathrm{ANeo}(\mathrm{SI})$ that contains a $B c i V I$ restriction recognition sequence downstream from the HCV sequence, permitting the runoff transcription of synthetic RNAs with 3' termini that are identical to the authentic HCV 3' terminus. It was constructed using Quick-Change (Stratagene) mutagenesis, first introducing the $B c i$ VI site downstream from the HCV sequence in pHCV-N $\Delta$ Cla. Two BciVI sites that were located in the Neo and $4 \mathrm{~B}$ coding regions (nt $5657 \mathrm{G}$ to $\mathrm{C}$, $\mathrm{HCV}-\mathrm{N}$ ) of pNtat $2 \mathrm{ANeo}(\mathrm{SI})$ were similarly removed by site-directed mutagenesis without changing the amino acid sequence of the polyprotein. $\mathrm{pU}-\mathrm{Bci} \mathrm{VI}$ was subsequently assembled by a threeway ligation of fragments containing each of these changes. To construct pC-BciVI, pA-BciVI, and pG-BciVI, PCR was carried out with primer pairs in which the forward primer contained the ClaI site located within the NS5B-coding sequence and the reverse primer contained different $3^{\prime}$ terminal nucleotides followed by the $\mathrm{XbaI}$ site. The PCR amplimers were subsequently ligated into pU$B c i$ I at the ClaI and XbaI sites. The DNA sequences of the manipulated regions were verified in the final construct before its use in transcription reactions for replication assays. Where indicated, additional $\triangle \mathrm{GDD}$ mutations that are lethal for replication were constructed in these genetic backgrounds by QuickChange mutagenesis using primer pairs that remove 10 amino acids from the NS5B sequence (Yi and Lemon 2002).

\section{RNA transcription and transfection}

RNA was synthesized with T7 MEGAScript reagents (Ambion), after linearizing plasmids with $\mathrm{XbaI}$, except in the case of $\mathrm{pU}$ - 
$B c i V I$, where BciVI was used to linearize the plasmid. Following treatment with RNase-free DNase to remove template DNA and precipitation of the RNA with lithium chloride, the RNA was transfected into En5-3 cells by electroporation. Briefly, $5 \mu \mathrm{g}$ RNA were mixed with $2 \times 10^{6}$ cells suspended in $500 \mu$ phosphatebuffered saline, in a cuvette with a gap width of $0.2 \mathrm{~cm}$ (Bio-Rad). Electroporation was with two pulses of current delivered by the Gene Pulser II electoporation device (Bio-Rad), set at $1.5 \mathrm{kV}, 25$ $\mathrm{uF}$, and maximum resistance. The transfected cells were transferred to two wells of a six-well tissue culture plate, and culture medium removed completely every $24 \mathrm{~h}$ and saved at $4^{\circ} \mathrm{C}$ for subsequent SEAP assay. The cells were washed twice with PBS prior to refeeding with fresh culture medium.

\section{Alkaline phosphatase assay}

SEAP activity was measured in $20-\mu \mathrm{l}$ aliquots of transfected cell supernatant culture fluids using the Phospha-Light Chemiluminescent Reporter Assay (Tropix) with the manufacturer's suggested protocol reduced in scale by a factor of 3 . The luminescent signal was read using a TD-20/20 Luminometer (Turner Designs, Inc.). Because the culture medium was replaced every $24 \mathrm{~h}$ in the transient transfection assays (see above), the SEAP activity measured in these fluids reflected the daily production of SEAP by the cells.

\section{Sequence analysis of cDNA from replicating HCV RNAs}

HCV RNA was extracted from cells, converted to cDNA and amplified by PCR as described previously (Yi and Lemon 2002). First-strand cDNA synthesis was carried out with Superscript II reverse transcriptase (GIBCO BRL); pfu-Turbo DNA polymerase (Stratagene) was used for PCR amplification of the DNA. The amplified DNAs were subjected to direct sequencing using an ABI 9600 automatic DNA sequencer. To obtain the sequence of the $3^{\prime}$ terminal region, first-strand cDNA synthesis was carried out with a primer (TTCTCCATCCTTCTAGCTCT, HCV-N nt 8901-8918) targeting the negative-strand RNA. The cDNA was purified using the QIAquick PCR purification kit (Qiagen) to remove nucleotides, and tailed with dCTP using recombinant terminal deoxynucleotidyl transferase (GIBCO BRL). The poly(C)-tailed cDNA was subsequently amplified by PCR using primer pairs N-2884RG-s (CCTCAGATCATTGAAGGACTCCATGGTCTTAGC (nt 89919023 in the HCV genome, except for $\underline{G}$, which substituted for $\mathrm{C}$ in the HCV-N sequence) and Abridged-Xba (GCTCTAGAGCGGGI IGGGIIGGGIIG).

\section{Real-time RT-PCR quantitation of HCV RNA}

Quantitative RT-PCR assays were carried out using TaqMan chemistry on a Prism 7700 instrument (ABI). For detection and quantitation of HCV RNA, we used primers complementary to the 5'NTR region of HCV (Takeuchi et al. 1999), with in vitro transcribed HCV RNA included in the assays as a standard. Results were normalized to the estimated total RNA content of the sample, as determined by the abundance of cellular GAPDH mRNA detected in a similar real-time RT-PCR assay using reagents provided with Taqman GAPDH Control Reagents (Human) (Applied Biosystems).

\section{Northern analysis for HCV RNA}

We seeded replicon-bearing cells into $10-\mathrm{cm}$ plates at a density of $5 \times 10^{5}$ cells/plate, and harvested the RNA at day 4 . Total cellular RNAs were extracted with Trizol reagent (GIBCO BRL) and quantified by spectrophotometry at $260 \mathrm{~nm}$. Thirty micrograms of the total RNA extracted from each well were loaded onto a denaturing agarose-formaldehyde gel, subjected to electrophoresis, and transferred to positively charged Hybond-N+ nylon membranes (Amersham-Pharmacia Biotec) using reagents provided with the NorthernMax Kit (Ambion). RNAs were immobilized on the membranes by UV crosslinking. The membrane was hybridized with a $\left[{ }^{32} \mathrm{P}\right]$-labeled antisense riboprobe complementary to the $3^{\prime}$ end of the HCV NS5B sequence (nt 8990-9275), and the hybridized probe was detected by exposure to X-ray film.

\section{ACKNOWLEDGMENTS}

This work was supported in part by grants from the National Institute of Allergy and Infectious Diseases (U19-AI40035) and the Texas Advanced Technology Program (004952-0027-2001). We thank Frank Scholle and Kui Li for their critical review of the manuscript.

The publication costs of this article were defrayed in part by payment of page charges. This article must therefore be hereby marked "advertisement" in accordance with 18 USC section 1734 solely to indicate this fact.

Received September 29, 2002; accepted December 9, 2002.

\section{REFERENCES}

Alter, M.J., Mast, E.E., Moyer, L.A., and Margolis, H.S. 1998. Hepatitis C. Infect. Dis. Clin. North Am. 12: 13-26.

Blight, K.J. and Rice, C.M. 1997. Secondary structure determination of the conserved 98-base sequence at the $3^{\prime}$ terminus of hepatitis $\mathrm{C}$ virus genome RNA. J. Virol. 71: 7345-7352.

Blight, K.J., Kolykhalov, A.A., Reed, K.E., Agapov, E.V., and Rice, C.M. 1998. Molecular virology of hepatitis C virus: An update with respect to potential antiviral targets. Antivir. Ther. 3: 71-81.

Bukh, J., Miller, R.H., and Purcell, R.H. 1995. Genetic heterogeneity of hepatitis C virus: Quasispecies and genotypes. Semin. Liv. Dis. 15: 41-63.

Choo, Q.-L., Kuo, G., Weiner, A.J., Overby, L.R., Bradley, D.W., and Houghton, M. 1989. Isolation of a cDNA clone derived from a blood-borne non-A, non-B viral hepatitis genome. Science 244: 359-362.

Choo, Q.-L., Richman, K.H., Han, J.H., Berger, K., Lee, C., Dong, C., Gallegos, C., Coit, D., Medina-Selby, A., Barr, P.J., et al. 1991. Genetic organization and diversity of the hepatitis $\mathrm{C}$ virus. Proc. Natl. Acad. Sci. 88: 2451-2455.

De Francesco, R. 1999. Molecular virology of the hepatitis C virus. J. Hepatol. 31 (Suppl 1): 47-53.

De Francesco, R., Neddermann, P., Tomei, L., Steinkuhler, C., Gallinari, P., and Folgori, A. 2000. Biochemical and immunologic properties of the nonstructural proteins of the hepatitis $C$ virus: Implications for development of antiviral agents and vaccines. Semin. Liver. Dis. 20: 69-83.

Egger, D., Wolk, B., Gosert, R., Bianchi, L., Blum, H.E., Moradpour, 
D., and Bienz, K. 2002. Expression of hepatitis C virus proteins induces distinct membrane alterations including a candidate viral replication complex. J. Virol. 76: 5974-5984.

Ferrari, E., Wright-Minogue, J., Fang, J.W.S., Baroudy, B.M., Lau, J.Y.N., and Hong, Z. 1999. Characterization of soluble hepatitis C virus RNA-dependent RNA polymerase expressed in Escherichia coli. J. Virol. 73: 1649-1654.

Friebe, P. and Bartenschlager, R. 2002. Genetic analysis of sequences in the $3^{\prime}$ nontranslated region of hepatitis $\mathrm{C}$ virus that are important for RNA replication. J. Virol. 76: 5326-5338.

Hong, Z., Cameron, C.E., Walker, M.P., Castro, C., Yao, N., Lau, J.Y., and Zhong, W. 2001. A novel mechanism to ensure terminal initiation by hepatitis C virus NS5B polymerase. Virology 285: 6-11.

Ikeda, M., Yi, M., Li, K., and Lemon, S.M. 2002. Selectable subgenomic and genome-length dicistronic RNAs derived from an infectious molecular clone of the HCV-N strain of hepatitis C virus replicate efficiently in cultured Huh7 cells. J. Virol. 76: 2997-3006.

Ito, T. and Lai, M.M. 1997. Determination of the secondary structure of and cellular protein binding to the $3^{\prime}$-untranslated region of the hepatitis C virus RNA genome. J. Virol. 71: 8698-8706.

Kim, M., Kim, H., Cho, S.P., and Min, M.K. 2002. Template requirements for de novo RNA synthesis by hepatitis $\mathrm{C}$ virus nonstructural protein 5B polymerase on the viral X RNA. J. Virol. 76: 6944-6956.

Kolykhalov, A.A., Feinstone, S.M., and Rice, C.M. 1996. Identification of a highly conserved sequence element at the $3^{\prime}$ terminus of hepatitis C virus genome RNA. J. Virol. 70: 3363-3371.

Kolykhalov, A.A., Mihalik, K., Feinstone, S.M., and Rice, C.M. 2000. Hepatitis $C$ virus-encoded enzymatic activities and conserved RNA elements in the $3^{\prime}$ nontranslated region are essential for virus replication in vivo. J. Virol. 74: 2046-2051.

Lindsay, K.L., Trepo, C., Heintges, T., Shiffman, M.L., Gordon, S.C., Hoefs, J.C., Schiff, E.R., Goodman, Z.D., Laughlin, M., Yao, R., et al. 2001. A randomized, double-blind trial comparing pegylated interferon $a l f a-2 b$ to interferon alfa- $2 b$ as initial treatment for chronic hepatitis C. Hepatology 34: 395-403.

Lohmann, V., Roos, A., Korner, F., Koch, J.O., and Bartenschlager, R. 1998. Biochemical and kinetic analyses of NS5B RNA-dependent RNA polymerase of the hepatitis C virus. Virology 249: 108-118.

Lohmann, V., Korner, F., Koch, J., Herian, U., Theilmann, L., and Bartenschlager, R. 1999. Replication of subgenomic hepatitis C virus RNAs in a hepatoma cell line. Science 285: 110-113.

Lohmann, V., Korner, F., Dobierzewska, A., and Bartenschlager, R. 2001. Mutations in hepatitis C virus RNAs conferring cell culture adaptation. J. Virol. 75: 1437-1449.

Major, M.E. and Feinstone, S.M. 1997. The molecular virology of hepatitis C. Hepatology 25: 1527-1538.

McHutchison, J.G., Gordon, S.C., Schiff, E.R., Shiffman, M.L., Lee,
W.M., Rustgi, V.K., Goodman, Z.D., Ling, M.H., Cort, S., and Albrecht, J.K. 1998. Interferon alfa-2b alone or in combination with ribavirin as initial treatment for chronic hepatitis C. Hepatitis Interventional Therapy Group. N. Engl. J. Med. 339: 1485-1492.

Mottola, G., Cardinali, G., Ceccacci, A., Trozzi, C., Bartholomew, L., Torrisi, M.R., Pedrazzini, E., Bonatti, S., and Migliaccio, G. 2002. Hepatitis $C$ virus nonstructural proteins are localized in a modified endoplasmic reticulum of cells expressing viral subgenomic replicons. Virology 293: 31-43.

Oh, J.W., Ito, T., and Lai, M.M. 1999. A recombinant hepatitis C virus RNA-dependent RNA polymerase capable of copying the fulllength viral RNA. J. Virol. 73: 7694-7702.

Oh, J.W., Sheu, G.T., and Lai, M.M. 2000. Template requirement and initiation site selection by hepatitis $\mathrm{C}$ virus polymerase on a minimal viral RNA template. J. Biol. Chem. 275: 17710-17717.

Pellerin, C., Lefebvre, S., Little, M.J., McKercher, G., Lamarre, D., and Kukolj, G. 2002. Internal initiation sites of de novo RNA synthesis within the hepatitis $\mathrm{C}$ virus polypyrimidine tract. Biochem. Biophys. Res. Commun. 295: 682-688.

Pietschmann, T., Lohmann, V., Kaul, A., Krieger, N., Rinck, G., Rutter, G., Strand, D., and Bartenschlager, R. 2002. Persistent and transient replication of full-length hepatitis $\mathrm{C}$ virus genomes in cell culture. J. Virol. 76: 4008-4021.

Seeff, L.B. 1997. Natural history of hepatitis C. Hepatology 26: 21S-28S.

Shim, J.H., Larson, G., Wu, J.Z., and Hong, Z. 2002. Selection of $3^{\prime}$-template bases and initiating nucleotides by hepatitis $C$ virus NS5B RNA-dependent RNA polymerase. J. Virol. 76: 7030-7039.

Takeuchi, T., Katsume, A., Tanaka, T., Abe, A., Inoue, K., TsukiyamaKohara, K., Kawaguchi, R., Tanaka, S., and Kohara, M. 1999. Realtime detection system for quantification of Hepatitis C virus genome. Gastroenterology 116: 636-642.

Tanaka, T., Kato, N., Cho, M.J., Sugiyama, K., and Shimotohno, K. 1996. Structure of the $3^{\prime}$ terminus of the hepatitis $\mathrm{C}$ virus genome. J. Virol. 70: 3307-3312.

Yamada, N., Tanihara, K., Takada, A., Yorihuzi, T., Tsutsumi, M., Shimomura, H., Tsuji, T., and Date, T. 1996. Genetic organization and diversity of the $3^{\prime}$ noncoding region of the hepatitis $\mathrm{C}$ virus genome. Virology 223: 255-261.

Yanagi, M., St Claire, M., Emerson, S.U., Purcell, R.H., and Bukh, J. 1999. In vivo analysis of the $3^{\prime}$ untranslated region of the hepatitis $\mathrm{C}$ virus after in vitro mutagenesis of an infectious cDNA clone. Proc. Natl. Acad. Sci. 96: 2291-2295.

Yi, M. and Lemon, S.M. 2002. 3' Nontranslated RNA signals required for replication of hepatitis C virus RNA. J. Virol. (in press).

Yi, M., Bodola, F., and Lemon, S. M. 2002. Subgenomic hepatitis C virus $(\mathrm{HCV})$ replicons inducing expression of a secreted enzymatic reporter protein. Virology 304: 197-210. 

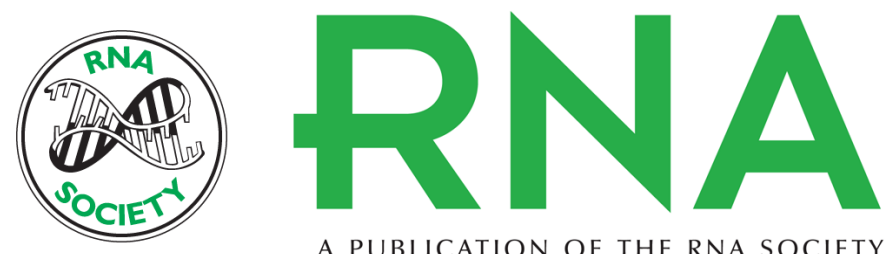

A PUBLICATION OF THE RNA SOCIETY

\section{Structure-function analysis of the $3^{\prime}$ stem-loop of hepatitis $C$ virus genomic RNA and its role in viral RNA replication}

MINKYUNG YI and STANLEY M. LEMON

RNA 2003 9: 331-345

References This article cites 34 articles, 18 of which can be accessed free at: http://rnajournal.cshlp.org/content/9/3/331.full.html\#ref-list-1

License

Email Alerting Receive free email alerts when new articles cite this article - sign up in the box at the Service top right corner of the article or click here.

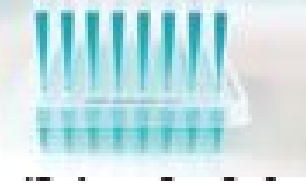

Providing Precise Solutions for your research.

To subscribe to RNA go to:

http://rnajournal.cshlp.org/subscriptions 